\title{
Terpenoid emissions from Quercus robur. A case study of Galicia (NW Spain)
}

\author{
Débora Pérez-Rial, ${ }^{* a}$ Josep Peñuelas, $^{b}$ Purificación López-Mahía ${ }^{a}$ and Joan Llusià ${ }^{b}$
}

\author{
Received 10th November 2008, Accepted 1st April 2009 \\ First published as an Advance Article on the web 21st April 2009 \\ DOI: $10.1039 / b 819960 d$
}

\begin{abstract}
Isoprene and monoterpenes emission fluxes emitted by Quercus robur seedlings were measured at a leaf scale in the field. Isoprene emissions were always predominant over the monoterpene ones, $\alpha$-pinene, $\beta$-pinene and camphene being the most abundant emitted monoterpenes. Emission fluxes were normalised at standard conditions of temperature and photosynthetically active radiation, $\mathrm{PAR},\left(30^{\circ} \mathrm{C}\right.$ and $1000 \mu \mathrm{mol} \mathrm{m} \mathrm{m}^{-2} \mathrm{~s}^{-1}$ respectively) using temperature and light dependent algorithms. The standardised emission fluxes ranged from 43 to $73 \mu \mathrm{g} \mathrm{g}_{\mathrm{DM}^{-1}} \mathrm{~h}^{-1}$ for isoprene and from 0.04 to $2.95 \mu \mathrm{g}$ $\mathrm{g}_{\mathrm{DM}}{ }^{-1} \mathrm{~h}^{-1}$ for the monoterpenes. The values reported in the literature are within our experimental intervals. These standardised fluxes were used to estimate the Quercus robur emissions in Galicia (NW Spain). This region is characterised by its abundant forest extensions where Quercus robur occupies the second place in species abundance with a total of 195029 ha of Quercus robur pure stands. To estimate the region emission fluxes, both the extension and distribution of the forest areas and the regional climatic conditions over five years (2002-2006) were taken into account. The averaged annual fluxes regarding the forest extension were $0.04 \mathrm{tha}^{-1} \mathrm{yr}^{-1}$ for isoprene and $0.52 \mathrm{~kg} \mathrm{ha}^{-1} \mathrm{yr}^{-1}$ for monoterpenes. This means averaged annual fluxes of $9730 \mathrm{t} \mathrm{yr}^{-1}$ and $114 \mathrm{t} \mathrm{yr}^{-1}$ for isoprene and monoterpenes, respectively. These values place Galicia as an important isoprene emitter power in Spain as a consequence of the extension of its forests more than of the climatic conditions.
\end{abstract}

\section{Introduction}

Vegetation constitutes a very important source of volatile organic compounds (VOCs) into the atmosphere. Biogenic volatile organic compounds (BVOCs) include isoprene, monoterpenes, alkanes, alkenes, carbonyl compounds, alcohols, esters, ethers and acids. The most studied group is the one called the isoprenoids or terpenoids where isoprene and monoterpenes are included. ${ }^{1,2}$ These compounds have been so widely studied because, as a consequence of their high reactivities, they have a great impact on both regional and global air quality. Terpenoids play a very dynamic role in the photochemical production of oxidants ${ }^{3}$ and they can be either a source or a sink for ozone, depending on the presence of $\mathrm{NO}_{\mathrm{x}}$. Isoprenoids are involved in reactions with hydroxyl radicals, ozone, nitrates and sulfates, producing ketones, aldehydes and $\mathrm{CO}^{4-6}$ Isoprene and monoterpene emissions can also take part in the formation of secondary organic aerosol with its implications for the radiative balance of the Earth ${ }^{7-9}$ and in the climate change, since they alter the concentrations of some greenhouse gases. ${ }^{10}$ Apart from their active role in tropospheric chemistry, the magnitude of the emissions of terpenoid compounds is also important regarding the global carbon cycle. Guenther et al. ${ }^{11}$ have estimated a natural VOC global emission of $1150 \mathrm{TgC}$ for the year 1990

${ }^{a}$ Department of Analytical Chemistry, University of A Coruña, Campus da Zapateira s/n,E-15071 A Coruña, Spain.E-mail: dperez@udc.es; Fax: +34 981167065; Tel: +34981167000 Extension 2187

${ }^{b}$ Unitat d'Ecofosiologia CSIC-CEAB-CREAF (Center for Ecological Research and Forestry Applications), Edifici C, Universitat Autònoma de Barcelona, E-08193 Bellaterra, Barcelona, Spain. E-mail: josep. penuelas@uab.cat; Fax: +34 935814151; Tel: +34 935811312 and, in a global scale, the annual flux of isoprene has a similar magnitude to the flux of methane.

Galicia is a region situated on the northwest of the Iberian Peninsula. It is located between $43^{\circ} 48^{\prime}$ and $41^{\circ} 49^{\prime} \mathrm{N}$ and $6^{\circ} 44^{\prime}$ and $9^{\circ} 18^{\prime} \mathrm{W}$ with an extension of $29574 \mathrm{~km}^{2}$ and a population of 2772533 inhabitants (2007). Administratively it is divided into four provinces, three of them being coastal regions and the fourth completely interior (figure 1). Galicia is characterised by an oceanic climate which provides abundant rainfall, high relative humidity and mild temperatures along the whole year. However, the most interior areas have a continental Mediterranean climate, with cool temperatures during the winter and autumn, but with high temperatures and severe droughts along the summer season. Regarding the economy, there is a big difference between the industrialised western coast areas and the east regions, with an economy based on the exploitation of the natural resources. According to the Third National Forest Inventory ${ }^{12}$ Galicia has a total of 1425000 ha of tree wooded areas, Pinus pinaster (maritime pine), Quercus robur (English oak or pedunculate oak) and Eucalyptus globulus (blue gum) being the most abundant tree species. The Quercus robur is a native species from this area (an autocthonous species). In contrast, Pinus pinaster and Eucalyptus globulus are alien (allocthonous) species in Galicia.

The aims of this study were (i) to measure the instantaneous emission rate for the BVOCs emitted by the dominant autocthonous tree species in Galicia, Quercus robur, in conditions of light saturation, and (ii) to estimate the BVOC emissions from Quercus robur in Galicia using the experimentally determined emission fluxes, the biomass data of Quercus robur stands and the meteorological data in this region during five years (2002-2006). 


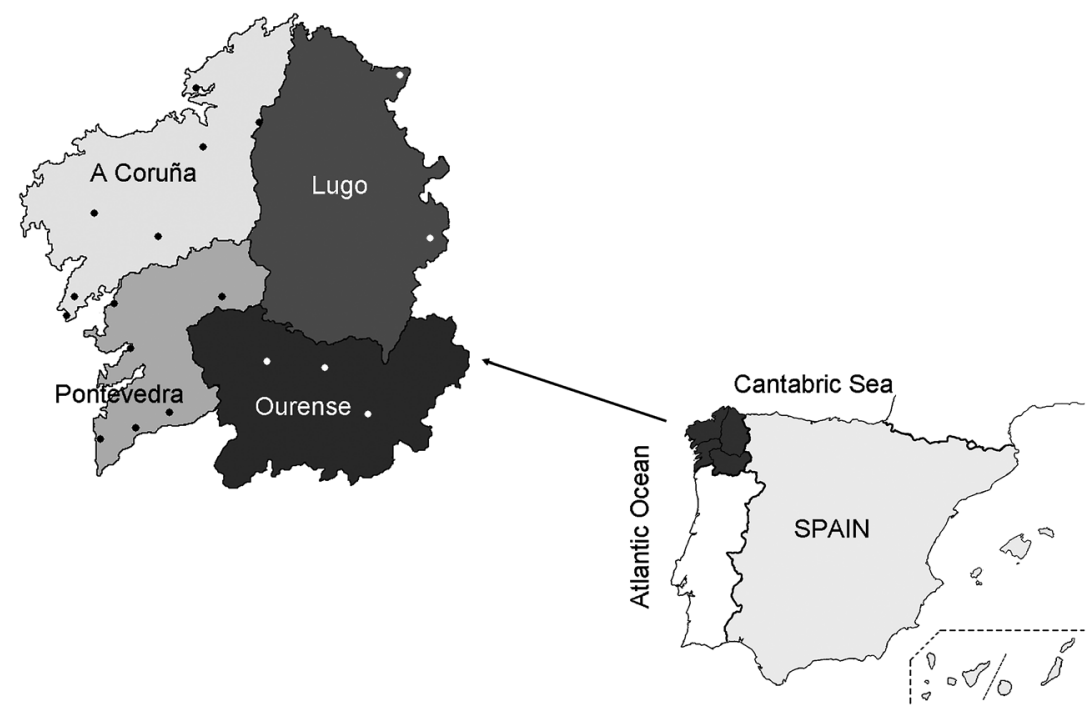

Fig. 1 Galicia and its administrative divisions. Situation of the meteorological stations in the year 2006.

\section{Material and methods}

\section{Plant material}

Two-year-old potted Quercus robur plants from a local nursery (Forestal Catalana, St. Feliu de Buixalleu, Girona) were used to carry out the experimental research. When the plants were acquired from the nursery, the leaf emergence after the winter season had already started. Plants were grown in the exterior of the Faculty of Sciences of the Universitat Autònoma de Barcelona (Bellaterra, Barcelona) where all the measurements were conducted. Quercus robur plants were well irrigated for a couple of weeks before the beginning of the experiments.

\section{Gas exchange}

$\mathrm{CO}_{2}$ and $\mathrm{H}_{2} \mathrm{O}$ exchanges were measured using a non-dispersive infrared gas analyser (IRGA) ADC-LCA4 (ADC Inc. Hoddesdon, Hertfordshire, UK) coupled with a PLC2P (ADC Inc.) leaf cuvette. In order to determine the VOC emissions exiting from the cuvette, a T-system was employed to split the air flow into two currents. One of these currents was led through an adsorbent trap and the other to the gas analyser. VOCs were not sampled until the photosynthesis and leaf gas exchange were stabilised. Two different kinds of adsorbent traps were alternately used. The first one was a multiadsorbent trap formed by three carbon based adsorbents and the second type was a polymeric trap. Stainless steel adsorbent cartridges from PerkinElmer (Norwak, CT, USA) were manually filled with Carbosieve SIII (40 mg), Carbotrap B (64 mg) and Carbotrap C (96 mg), (multiadsorbent traps) or with Tenax TA (200 mg) for the simple traps (all the adsorbents from Supelco, Bellefonte PA, USA). In the multibed traps individual adsorbent layers were separated by plugs of quartz wool. Before their first use, traps were conditioned at 350 ${ }^{\circ} \mathrm{C}$ (carbonaceous traps) or at $300{ }^{\circ} \mathrm{C}$ (Tenax TA traps) for four hours and, previous to the sampling, they were heated at the same temperature during ten minutes under a helium flow. To minimize the risk of contamination during the transport to the sampling site, adsorbent tubes were individually stored in glass jars sealed with Teflon lids and these jars were put into a box filled with a bed of activated charcoal.

Gaseous samples were taken forcing the air to pass through the adsorbent cartridges using a Silent Air 3 diaphragm pump (Penn Plax, NY, USA) with sampling flows ranging from 90 to $110 \mathrm{~mL}$ $\min ^{-1}$ during 10 minutes. The flow through each individual tube was controlled using a previously calibrated rotameter. Samples were taken in field conditions and only on sunny cloudless days. After the sampling, tubes were transported to the laboratory using a portable refrigerator $\left(4^{\circ} \mathrm{C}\right)$ and stored at $-30{ }^{\circ} \mathrm{C}$ until analysis.

At the end of the sampling, leaf areas were measured with a LiCor 3100 Area Meter (Li-Cor Inc., Lincoln, NE) and, after that, leaves were dried at $60{ }^{\circ} \mathrm{C}$ until constant weight, with the aim of determining the leaf areas and dry weights.

\section{Instrumental analyses}

Samples were analysed with thermal desorption coupled with gas chromatography with mass spectrometry detection (TD/GC/ MSD), all the equipment was from PerkinElmer. An ATD-400 was employed to carry out the thermal desorption in two steps. The primary desorption was developed at $350^{\circ} \mathrm{C}$ (carbonaceous traps) or at $300{ }^{\circ} \mathrm{C}$ (Tenax TA traps) for 5 minutes and then the desorbed VOCs were cryo-focused onto a Tenax TA secondary trap at $-30{ }^{\circ} \mathrm{C}$. In the next step this trap was quickly heated to $300{ }^{\circ} \mathrm{C}$ with a rate of $40{ }^{\circ} \mathrm{C} \mathrm{s}^{-1}$ and kept at that temperature for 4 minutes. Separation was performed using an AutoSystem chromatograph equipped with a capillary ZB-624 column (Phenomenex, Torrance, CA, USA), $60 \mathrm{~m} \times 0.32 \mathrm{~mm} \times 1.8 \mu \mathrm{m}$ film thickness, subjected to the following temperature program: from $46{ }^{\circ} \mathrm{C}$ to $70^{\circ} \mathrm{C}$ at $30{ }^{\circ} \mathrm{C} \mathrm{min}{ }^{-1}$, to $150{ }^{\circ} \mathrm{C}(5 \mathrm{~min})$ at $10{ }^{\circ} \mathrm{C} \mathrm{min}{ }^{-1}$

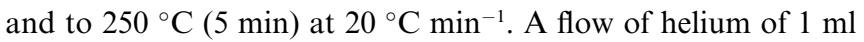
$\min ^{-1}$ was used as carrier gas. A mass spectrometer TurboMass operated by TurboMass Ver4.1.1 software was employed to carry out the peak detection and data acquisition. The spectrometer scanned from 35 to $200 \mathrm{amu}$ in electron ionization 
mode $(70 \mathrm{eV})$ and the transfer line and source temperatures were $250{ }^{\circ} \mathrm{C}$.

Quantitative analyses were carried out using the external standard method. Isoprene, camphene, cineol, limonene, $\alpha$-pinene, $\beta$-pinene, $\gamma$-terpinene (Sigma-Aldrich, Bellefonte, PA, USA), $\Delta^{3}$-carene, ocimene, $\alpha$-phellandrene, $\alpha$-terpinene and linalool (Fluka Chemic, Bellefonte, PA), pure standards were used to prepare gravimetrically both individual and multicomponent methanolic solutions. Qualitative analyses were developed taking into account the information provided by the mass spectrometer and the retention times achieved in the chromatographic separation.

\section{Normalised emission rates}

The instantaneous emission rates were normalised at standard conditions of photosynthetically active radiation (PAR) and temperature according to Guenther et al. ${ }^{13,11} \mathrm{We}$ used the temperature and light dependent model for non-storing species such as the studied Quercus robur.

The algorithm related to the non-storing species is:

$$
\mathrm{E}=\mathrm{E}_{\mathrm{S}} \times \mathrm{C}_{\mathrm{L}} \times \mathrm{C}_{\mathrm{T}}
$$

where $E$ is the instantaneous emission rate ( $\mu \mathrm{g}$ terpenoid $\mathrm{g}_{\mathrm{DM}}{ }^{-1}$ $\left.\mathrm{h}^{-1}\right)$ in environmental conditions of $T(\mathrm{~K})$ and $P A R\left(\mu \mathrm{mol} \mathrm{m}{ }^{-2}\right.$ $\left.\mathrm{s}^{-1}\right), E_{S}$ is the emission rate in standard conditions of temperature, $T_{S}(303 \mathrm{~K})$ and PAR $\left(1000 \mu \mathrm{mol} \mathrm{m}^{-2} \mathrm{~s}^{-1}\right)$ and $C_{T}$ and $C_{L}$ are functions of the temperature and PAR respectively, according to the equations [2] and [3]:

$$
\begin{gathered}
\mathrm{C}_{\mathrm{T}}=\frac{\exp \frac{\mathrm{C}_{\mathrm{T} 1} \times\left(\mathrm{T}-\mathrm{T}_{\mathrm{S}}\right)}{\mathrm{R} \times \mathrm{T}_{\mathrm{S}} \times \mathrm{T}}}{1+\exp \frac{\mathrm{C}_{\mathrm{T} 2} \times\left(\mathrm{T}-\mathrm{T}_{\mathrm{M}}\right)}{\mathrm{R} \times \mathrm{T}_{\mathrm{S}} \times \mathrm{T}}} \\
\mathrm{C}_{\mathrm{L}}=\frac{\alpha \times \mathrm{C}_{\mathrm{L} 1} \times \mathrm{PAR}}{\sqrt{1+\alpha^{2} \times \mathrm{PAR}^{2}}}
\end{gathered}
$$

with $R=8.314 \mathrm{~J} \mathrm{~K}^{-1} \mathrm{~mol}^{-1}$ and $T_{M}=314 \mathrm{~K} . \alpha=0.0027, C_{L 1}=$ $1.066, C_{T 1}=95000 \mathrm{~J} \mathrm{~mol}^{-1}$ and $C_{T 2}=230000 \mathrm{~J} \mathrm{~mol}^{-1}$ are empirically determined coefficients.

\section{Regional estimation considering the climatic conditions in Galicia from 2002 to 2006}

Based on meteorological data for the years from 2002 to 2006 and taking into consideration the standardised emissions calculated with the experimental data, instantaneous emission rates were estimated for the four Galician provinces during these years. Climatic data were obtained from the Galician climatologic yearbooks for the years 2002 to $2006 .{ }^{14-18}$ The situation and number of the climatic stations recording both temperature and PAR in Galicia have increased along this time. The distribution of the climatic stations used for the year 2006 is shown in figure 1. It is important to take into account that the number and distribution of the meteorological stations does not show the real climatic situation in Galicia because they are not equally distributed along the whole territory. At the same time, the use of averaged climatic data according to the administrative division in provinces is only a way of simplifying the explanation of the results, but it does not obey to a criterion regarding the magnitude of the emissions. In the climatologic yearbooks the temperature, $\mathrm{T}\left({ }^{\circ} \mathrm{C}\right)$, and PAR data are arranged according to the province and month. In order to make the data handling easier, we have averaged the values of these parameters for each month and for all the stations belonging to the same province. Thus, we have obtained monthly averaged values of $T$ and PAR for each province along the five years.

\section{Statistical analyses}

Statistical descriptive analysis, anomalous detection analysis and paired sampled comparison analysis were conducted with Statgraphics Plus for Windows v. 5.0 (Statistical Graphics Corp., Herndon, VA, USA).

\section{Results and discussion}

\section{Instantaneous measurements and standardisation of the emission rates}

Isoprene and monoterpene emissions were determined using the two kinds of adsorbent traps. Most of the measurements were carried out with the carbonaceous traps but duplicates of the samples were taken using the Tenax TA cartridges. A samplepaired comparison analysis using a t-test (95\% confidence level) was carried out in order to establish if, in our conditions of work, both kinds of traps are comparable. The results demonstrated that the mean of the difference between the compounds compared individually is statically equal to zero in all the samples for all the compounds except for isoprene. Isoprene has been reported to be lost by up to $80 \%$ when molecular sieves (in our case Carbosieve SIII) are employed in the sampling, even immediately after the sampling step. ${ }^{19}$ So, in our work we have quantified the isoprene concentrations using the Tenax TA traps. Qualitative analysis of Tenax TA traps revealed the presence of limonene while it was not observed in the carbonaceous traps. We suppose that limonene can be a product of the dimerization of isoprene, thus isoprene concentrations reported on Tenax TA traps would be slightly lower than the actual values. In fact, we have quantified that the isoprene dimerization percentage during the generation of a gaseous standard from an isoprene liquid standard on Tenax TA traps is lower than $7 \%$.

All the measurements were carried out in environmental field conditions but always with an irradiance close to the standard condition of $1000 \mu \mathrm{mol} \mathrm{m} \mathrm{m}^{-2} \mathrm{~s}^{-1}$ and $30^{\circ} \mathrm{C}$. We worked with PAR ranging from 902.3 to $1386.0 \mu \mathrm{mol} \mathrm{m} \mathrm{m}^{-2} \mathrm{~s}^{-1}$ and temperatures from 300.5 to $309.8 \mathrm{~K}$, even when it has been reported ${ }^{20}$ that for Quercus robur isoprene emission is saturated at PAR values between 400 and $500 \mu \mathrm{mol} \mathrm{m} \mathrm{m}^{-2} \mathrm{~s}^{-1}$.

In all the samples isoprene was the most abundant BVOC with instantaneous emission rates fluctuating between 50.57 and 134.1 $\mu \mathrm{g}$ isoprene $\mathrm{g}_{\mathrm{DM}}{ }^{-1} \mathrm{~h}^{-1}$, while the total monoterpene sum ranged from 0.03 to $3.20 \mu \mathrm{g}$ monoterpene $\mathrm{g}_{\mathrm{DM}}{ }^{-1} \mathrm{~h}^{-1}$, $\mathrm{g}_{\mathrm{DM}}$ being the leaf dry mass expressed in grams. This corroborates the fact that Quercus robur is a strong isoprene emitter.

Regarding monoterpenes, $\alpha$-pinene was the most abundant of them in all the samples with instantaneous emission rates as high 
as $2.62 \mu \mathrm{g} \mathrm{g}_{\mathrm{DM}}{ }^{-1} \mathrm{~h}^{-1}\left(304 \mathrm{~K}, 908.4 \mu \mathrm{mol} \mathrm{m} \mathrm{m}^{-2} \mathrm{~s}^{-1}\right.$ of PAR). $\beta$-pinene and camphene were also present in most of the samples but with fluxes always lower than $0.40 \mu \mathrm{g} \mathrm{g}_{\mathrm{DM}}{ }^{-1} \mathrm{~h}^{-1}$. Occasionally, in a few samples, myrcene was also quantified with a maximum flux of $0.06 \mu \mathrm{g} \mathrm{g}_{\mathrm{DM}}{ }^{-1} \mathrm{~h}^{-1}$.

The trends of the emissions of both pinenes are correlated, with a linear correlation coefficient of 0.64 , but there is not such a linear correlation between $\alpha$-pinene and camphene $\left(\mathrm{R}^{2}=0.14\right)$ or between $\beta$-pinene and camphene $\left(\mathrm{R}^{2}=0.14\right)$.

The instantaneous emission rates normalised at standard conditions of PAR and temperature according to Guenther et $a .^{13,11}$ are shown in Table 1 . The standardised isoprene emissions that we have determined experimentally ranged from 43.30 to $72.79 \mu \mathrm{g} \mathrm{g}_{\mathrm{DM}}{ }^{-1} \mathrm{~h}^{-1}$, the averaged value being $58.28 \mu \mathrm{g} \mathrm{g}_{\mathrm{DM}}{ }^{-1}$ $\mathrm{h}^{-1}$. These data are consistent with those reported in the literature for Quercus robur. Hewitt and Street ${ }^{21}$ extended the emission interval from 40 to $76.6 \mu \mathrm{g} \mathrm{g}_{\mathrm{DM}^{-1}} \mathrm{~h}^{-1}$ in standard conditions. Simpson et $a .^{22}$ have gathered several data extracted from the literature (see references therein), and they have reported isoprene standardised emission factors for the United States (40 $\mu \mathrm{g} \mathrm{g}_{\mathrm{DM}}{ }^{-1} \mathrm{~h}^{-1}$, as the arithmetic mean of 20 and $\left.60 \mu \mathrm{g} \mathrm{g}_{\mathrm{DM}}{ }^{-1} \mathrm{~h}^{-1}\right)$, Europe (40 $\left.\mu \mathrm{g} \mathrm{g}_{\mathrm{DM}^{-1}} \mathrm{~h}^{-1}\right)$ and Russia $\left(60-100 \mu \mathrm{g} \mathrm{g}^{-1} \mathrm{~h}^{-1}\right.$ in fresh weight). In order to evaluate the temporal and spatial distribution of the non-methane hydrocarbons, NMHC, in Greece, Simeonidis et al. ${ }^{23}$ used an isoprene emission factor of $14.7 \mu \mathrm{g} \mathrm{g}^{-1}$ $\mathrm{h}^{-1}$ for oak (at $303 \mathrm{~K}, 800 \mu \mathrm{mol} \mathrm{m} \mathrm{m}^{-2} \mathrm{~s}^{-1}$ ), but they did not specify which were the species included in the term oak. To study the BVOC emissions in German forests Smiatek and Steinbrecher ${ }^{24}$ used emission rates extracted from public databases and other sources and, for Quercus robur, they reported an isoprene standardised emission factor of $60 \mu \mathrm{g} \mathrm{g}^{-1} \mathrm{~h}^{-1}$.

Although Quercus robur is a strong isoprene emitter, moderate monoterpene emissions from this species have also been reported. The database from Lancaster University (http://www.es. lancs.ac.uk/cnhgroup/cover.html) includes a monoterpene emission rate of $1.76 \mu \mathrm{g} \mathrm{g}_{\mathrm{DM}}{ }^{-1} \mathrm{~h}^{-1}$ for Quercus robur, $\alpha$-pinene and 1,8-cineol being noted as the main emitted monoterpenes. Besides this Guenther et al. ${ }^{25}$ reported a value of $0.2 \mu \mathrm{g} \mathrm{g}_{\mathrm{DM}}{ }^{-1} \mathrm{~h}^{-1}$ for the terpenes released from oaks while Smiatek and Steinbrecher $^{24}$ gave a value of $0.30 \mu \mathrm{g} \mathrm{g}_{\mathrm{DM}}{ }^{-1} \mathrm{~h}^{-1}$ for the sum of the emitted monoterpenes (mainly $\alpha$-pinene, $\beta$-pinene and limonene). They have also reported emissions of other BVOCs as methanol, hexenal or hexenol. The value from the database (1.76 $\left.\mu \mathrm{g} \mathrm{g}_{\mathrm{DM}}{ }^{-1} \mathrm{~h}^{-1}\right)$ is within our interval $\left(0.04-2.95 \mu \mathrm{g} \mathrm{g}_{\mathrm{DM}}{ }^{-1} \mathrm{~h}^{-1}\right)$ but far from our averaged value $\left(0.68 \mu \mathrm{g} \mathrm{g}_{\mathrm{DM}}{ }^{-1} \mathrm{~h}^{-1}\right)$. Monoterpene emissions reported by Guenther et al. ${ }^{25}$ and Smiatek and Steinbrecher ${ }^{24}$ are also included in our experimental range.
The qualitative composition reported in the literature for the monoterpene fraction is different from the observed in our experimental measurements. We have found a significant emission for both pinenes (especially for the $\alpha$ isomer) and camphene but we have not detected 1,8-cineol.

\section{Regional estimation considering the climatic conditions in Galicia from 2002 to 2006}

Table 2 summarises the average emission rates for the years from 2002 to 2006 calculated for isoprene and monoterpenes using the experimental leaf terpenoid emission data and the values of $\mathrm{T}$ and PAR reported in the meteorological stations of each province. The emission rates for both isoprene and monoterpenes grow from the beginning of the year to reach a maximum in the summertime (August or July) and, after that, the values of the emission rates begin to decline to get minimum values in the wintertime. Taking into account that the emission rates are obtained as the product of $\mathrm{C}_{\mathrm{L}}, \mathrm{C}_{\mathrm{T}}$ and a constant value for the average emission of isoprene or monoterpenes, $\mathrm{E}_{\mathrm{S}}$, the trend showed by the emission rates along the year in the Table 2 is only a consequence of the climatic conditions of each province. So, the western coast provinces show the highest average emission rates as a consequence of their temperate climate along the year while the emissions in the interior eastern provinces reflect the presence of more severe winters.

Figure 2 shows the evolution during these five years of the provincial isoprene emission rates estimated in response to the meteorological variables. The pattern followed by the emission rates along these five years is very similar from one year to another, with minimum emissions during the autumn and winter and growing emissions from spring to summer, as it was explained before. In the majority of the months the maximum emissions were achieved in Pontevedra because of several facts. First, its southern location provides a benign climate during the whole year and, besides this, the presence of the sea exerts an effect of thermoregulation which is reflected on these mild temperatures along the whole year, even in winter. It is also worth saying that the relative small size and the elongated shape of this province favours that the effect of the sea is noticed even in the most interior areas of Pontevedra. On the opposite side, it is the province of Ourense with the lowest emission rates during the winter because, as a consequence of its totally interior (continental) position, the temperatures in this area are very low during this season. Its interior location is also responsible for the high temperatures that increase the emissions in the summertime. During the year 2002 there was a clear difference between the

Table 1 Descriptive statistics for the terpenoid emissions $\left(\mu \mathrm{g} \mathrm{g}_{\mathrm{DM}^{-1}} \mathrm{~h}^{-1}\right)$ in standard conditions of temperature $T_{S}(303 \mathrm{~K})$ and PAR $\left(1000 \mu \mathrm{mol} \mathrm{m}{ }^{-2} \mathrm{~s}^{-1}\right)$

\begin{tabular}{lccccc}
\hline Compound & Mean & SD $^{a}$ & Median & Maximun & Minimun \\
\hline Isoprene & 58.28 & 14.77 & 58.52 & 72.79 & 43.30 \\
$\alpha$-Pinene & 0.53 & 0.70 & 0.24 & 0.41 & 0.28 \\
Camphene & 0.12 & 0.09 & 0.09 & 0.06 & 0.02 \\
Myrcene & 0.05 & 0.01 & 0.05 & 0.04 & 0.04 \\
$\beta$-Pinene & 0.07 & 0.80 & 0.42 & & 0.04 \\
EMonoterpenes & 0.68 & & & &
\end{tabular}


Table 2 Isoprene and $\Sigma$ monoterpenes averaged emission rates $\left(\mu \mathrm{g}_{\mathrm{DM}}{ }^{-1} \mathrm{month}^{-1}\right)$ for the Galician provinces from 2002-2006, considering only the climatic conditions (i.e. $\mathrm{C}_{\mathrm{L}}$ and $\mathrm{C}_{\mathrm{T}}$ ) and the daylight hours

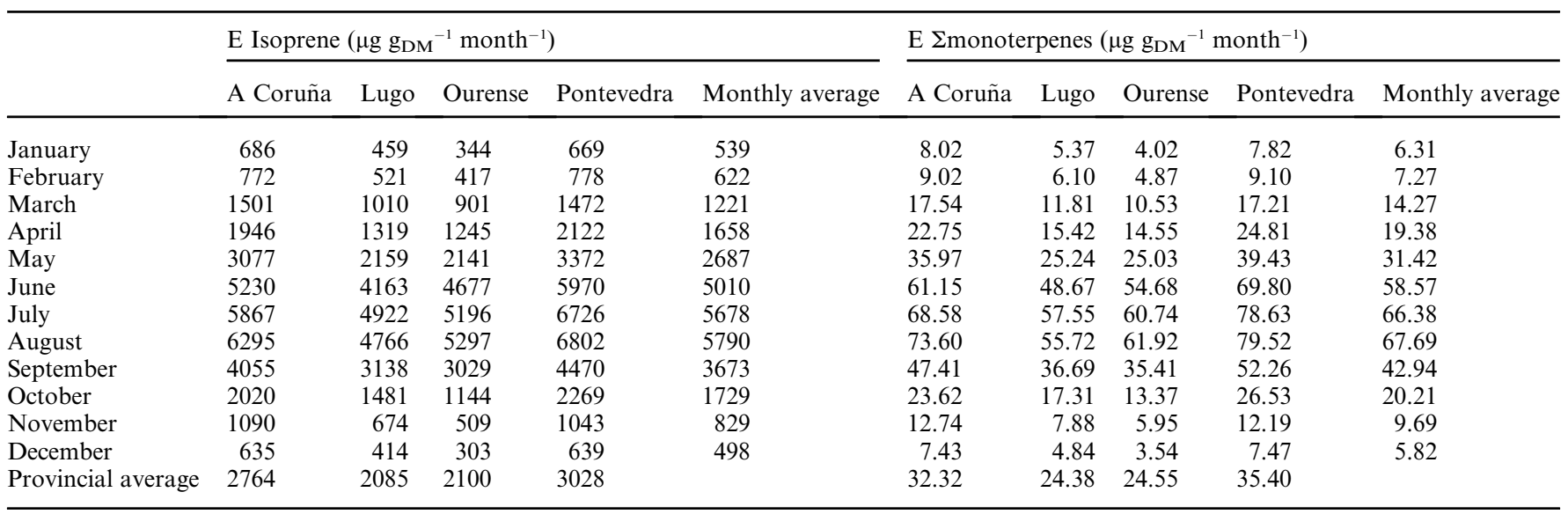

emissions in eastern provinces (taken together) and in western provinces but this difference was reduced along the years. In that year there were only nine stations reporting both temperature and PAR simultaneously in Galicia (versus 17 in the year 2006). From these nine stations, six were placed on the western provinces and only three on the east. Only two of the western stations were sited with an altitude higher than $100 \mathrm{~m}$ (but lower than 410 $\mathrm{m})$ while in the east the situation was radically different, with two of the three stations with an altitude higher than $950 \mathrm{~m}$. So, it is possible that the differences between the position and number of the western and eastern stations were responsible for the marked differences in the climatic recordings during that year between the eastern and western provinces. As the number of stations was growing along the years and their distribution was covering a broader extension, the actual climate in Galicia is better described, with differences between the east and the west but not as pronounced as the data for the year 2002 showed.

Apart from the comparison among the different administrative regions, it is also noticeable that there is an upward trend in the emissions along these five years, the maxima in summer being slightly higher every year. It can be seen that the generalised increasing temperatures, intensified by the climate change, is affecting the magnitude of the emissions of BVOCs. The summer emissions in 2003 were exceptionally high as a consequence of a heat wave that affected a great extension of Europe, especially Spain, Portugal, France and Italy, causing an increase in the BVOC emissions regarding the rest of the years.

Figure 2 shows the trend in the isoprene emission along these years. The evolution for the estimated monoterpene emissions in this period had the same pattern, since the same factors, $\mathrm{C}_{\mathrm{T}}$ and $\mathrm{C}_{\mathrm{L}}$, were used in the estimation; however, these terpene emissions presented lower values corresponding to the smaller values of $E_{S}$ for the monoterpenes (Table 1).

\section{Extrapolation to the Galician forests}

Detailed information on the extent of the Galician forest and species-type was extracted from the most recent forest inventory. ${ }^{12}$ The distribution of the Quercus robur stands in Galicia shows that Lugo is the province with the most extensive pure forests of this species (131175 ha), followed by Ourense (38854 ha), Pontevedra (14215 ha) and A Coruña (10785 ha). In addition, the inventory also reports the presence of mixed forest, but without specifying how much of the total extension is occupied

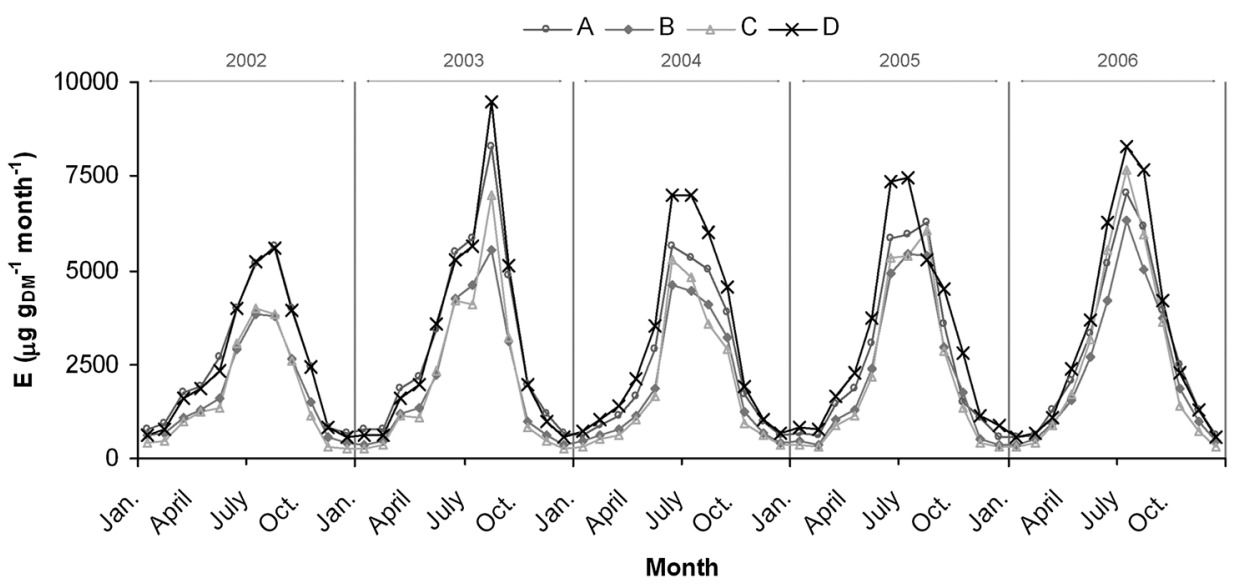

Fig. 2 Time course of the Quercus robur isoprene emission rates from 2002 to 2006 considering the calculated Es and the T and PAR for these years. A: A Coruña; B: Lugo; C: Ourense; D: Pontevedra. 
by oaks and by the other species. In these cases, and as a first approach, the total area of the mixed forest was divided by the number of the majority species coexisting in the same stand. Considering this, the areas occupied by Quercus robur in Pontevedra and A Coruña would be 29571 and 19105 ha respectively. According to this, the Quercus robur stands have a total extension of 218704 ha in Galicia.

To convert the calculated emission rates $\left(\mu \mathrm{g} \mathrm{g}_{\mathrm{DM}}{ }^{-1} \mathrm{~h}^{-1}\right)$ into emission fluxes referred to the extension of the forests $\left(\mu \mathrm{g} \mathrm{ha}^{-1}\right.$ $\mathrm{h}^{-1}$ ) it is necessary to estimate a leaf biomass factor or a biomass density ( $\mathrm{g}$ biomass $\mathrm{ha}^{-1}$ ) for the Quercus robur stands. In order to calculate this parameter we have used the total aerial biomass value for Quercus robur $\left(238 \mathrm{Mg} \mathrm{ha}^{-1}\right)$ and an estimation of the percentage of leaf biomass in the aerial total biomass $(2.1 \%) .{ }^{26} \mathrm{It}$ was also necessary to calculate the percentage of humidity of the oak leaves $(61.1 \pm 3.85 \%)$ to extend our cuvette emission measurements to the real forests. An ME215PE analytical balance (Sartorius AG, Goettingen, Germany) was used for this purpose. The biomass factor, $194 \mathrm{~g} \mathrm{~m}^{-2}$ (in dry weight), was multiplied by the species emission rate $\left(\mu \mathrm{g}_{\mathrm{DM}}{ }^{-1} \mathrm{~h}^{-1}\right)$, after considering the percentage of humidity, to estimate the biogenic hydrocarbon emission rate referred to the forest area $\left(\mu \mathrm{g} \mathrm{ha} \mathrm{h}^{-1}\right.$ $\mathrm{h}^{-1}$ ). Our calculated biomass factor is lower than the calculated ones by Simeonidis et al. ${ }^{23}\left(220 \mathrm{~g} \mathrm{~m}^{-2}\right.$ for a sparse forest and $400 \mathrm{~g}$ $\mathrm{m}^{-2}$ for a dense forest), by Smiatek and Steinbrecher ${ }^{24}$ (320 g $\mathrm{m}^{-2}$ ) or by Andreani-Aksoyoglu and $\operatorname{Keller}^{27}\left(530 \mathrm{~g} \mathrm{~m}^{-2}\right)$. It should be kept in mind that in these references authors do not clarify if their biomass factors are referred to as wet or dry mass.

Apart from all these previous considerations to estimate the mass of the leaves in Quercus robur, it is also necessary to introduce a corrective factor in order to describe the biomass decrease of the deciduous trees during the autumn and winter periods. Andreani-Aksoyoglu and $\mathrm{Keller}^{27}$ consider that deciduous species only emit isoprene during the daytime within the period between April and September, so the value that they use for this corrective factor during the rest of the year is 0 . Simeonidis et al. ${ }^{23}$ consider that the value of this factor is 0.5 for October, November and April and for December, January, February and March its value is 0 . We have considered the corrective factor cited by Simeonidis et $a .^{23}$ because this correction assumes a progressive decreasing and increase of the emission as a function of the leaf fall or emergence respectively, instead of a complete suppression of the emissions at the beginning of the autumn and at the end of the winter. The use of corrective factors agrees with the experimental data of Smiatek and Steinbrecher ${ }^{24}$ who modelled the VOC forest emissions in Germany for a whole year and proved that only $0.1 \%$ of isoprene, $2.5 \%$ of monoterpenes and $3.3 \%$ of other VOCs are emitted in the winter season. Symeonidis et al. ${ }^{28}$ have also estimated that, approximately, $94 \%$ of annual isoprene emissions are produced from May to September in the Balkan Peninsula.

The main results of the terpenoid emission rates considering the extension occupied by Quercus robur stands in Galicia are summarised in the Table 3. As it was expected, the emissions in Lugo are the highest in Galicia due to the vast extension of the forests in this province. The magnitude of the area occupied by Quercus robur prevails over the values of $\mathrm{C}_{\mathrm{L}}$ and $\mathrm{C}_{\mathrm{T}}$. So, despite having the third lowest emission values in relation to the other provinces when these emissions are expressed as a function of the climatic conditions, i.e. as a function of $\mathrm{C}_{\mathrm{T}}$ and $\mathrm{C}_{\mathrm{L}}$, (Table 2), Lugo occupies the top position when the forest area is considered.

The estimated BVOC emissions are higher in summer, when temperatures, radiation and plant biomass are the highest of the year. Figure 3 shows the evolution of the isoprene emissions regarding the province and taking into account the extension of the Quercus robur forests. Comparing figures 2 and 3 it is obvious the change in the positions of the provinces regarding the magnitude of the emissions when the extent of the stands is taken into account (figure 3) or not (figure 2).

During these five years, the averages of the Quercus robur emission fluxes were $9730 \mathrm{t} \mathrm{yr}^{-1}$ and $114 \mathrm{t} \mathrm{yr}^{-1}$ for isoprene and monoterpenes, respectively. Isoprene emissions ranged from 7691 to $11257 \mathrm{t} \mathrm{yr}^{-1}$ and monoterpenes from $90 \mathrm{t} \mathrm{yr}^{-1}$ to $132 \mathrm{t} \mathrm{yr}^{-1}$.

\section{Comparison with other inventories}

There are only few data of isoprene emission by Quercus robur in terms of $\mathrm{t} \mathrm{ha}^{-1} \mathrm{yr}^{-1}$ in the literature. For example, Anastasi

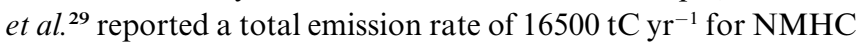
in the United Kingdom for a deciduous forest area of 698000 ha, but they did not specify how much of these emissions were isoprene or monoterpenes. Neither did they clarify the composition of the deciduous forests. Isidorov et al. ${ }^{20}$ reported that the emission for isoprene in Polish forest ranges from 38900 to $135800 \mathrm{t} \mathrm{yr}^{-1}$ depending on the weather conditions but, although they reported the area occupied by the stands of Quercus robur (557964 ha), they did not specify the contribution of this species to the isoprene total emission. Andreani-Aksoyoglu and Keller ${ }^{27}$ in their inventory for the isoprenoid emissions from Swiss forests reported data of isoprene emission referred to the extension of the forests. Working with their data, we estimate that the Quercus robur isoprene emission rate in Switzerland is $0.096 \mathrm{t}$ isoprene $\mathrm{ha}^{-1} \mathrm{yr}^{-1}$, our estimation for the Galician forest being smaller than this $\left(0.044 \mathrm{t}\right.$ isoprene $\left.\mathrm{ha}^{-1} \mathrm{yr}^{-1}\right)$. It is noticeable that the emissions for Switzerland were calculated using the algorithms developed by Tingey while in this work the Guenther's algorithms were used. Another important difference lies in the value of the biomass factor used for the Swiss forests $\left(530 \mathrm{~g} \mathrm{~m}^{-2}\right)$ and the value for the same factor considered in this work $\left(194 \mathrm{~g} \mathrm{~m}^{-2}\right)$.

Simpson et $a .^{22}$ estimated the isoprene emissions for various European countries using different models and within them, the Guenther 93 algorithm. Using this model and emission data for isoprene extracted from American and European literature for the main forest categories (see references therein), they estimated a value for the isoprene emission in Spain of $137800 \mathrm{t} \mathrm{yr}^{-1}$. They consider that the extension of oak forests in Spain is 5380000 ha and these forests emit $79100 \mathrm{t}$ isoprene $\mathrm{yr}^{-1}$, that results in an annual emission of $0.015 \mathrm{tha}^{-1} \mathrm{yr}^{-1}$. This value is smaller than the one calculated for Galicia $\left(0.044 \mathrm{t} \mathrm{ha}^{-1} \mathrm{yr}^{-1}\right)$. Anyway, it is important to note that data from Simpson et al. ${ }^{22}$ are referred to oak but they do not specify which species are included in that term, so they are taking into consideration different kinds of oaks that are weaker isoprene emitters than Quercus robur (i.e Quercus ilex) and with different biomass densities. It is remarkable that Quercus robur is the second species with the highest 
Table 3 Isoprene and $\Sigma$ monoterpenes averaged emission rates (ton month ${ }^{-1}$ ) for the Galician provinces from $2002-2006$ considering both climatic conditions and the forest extension

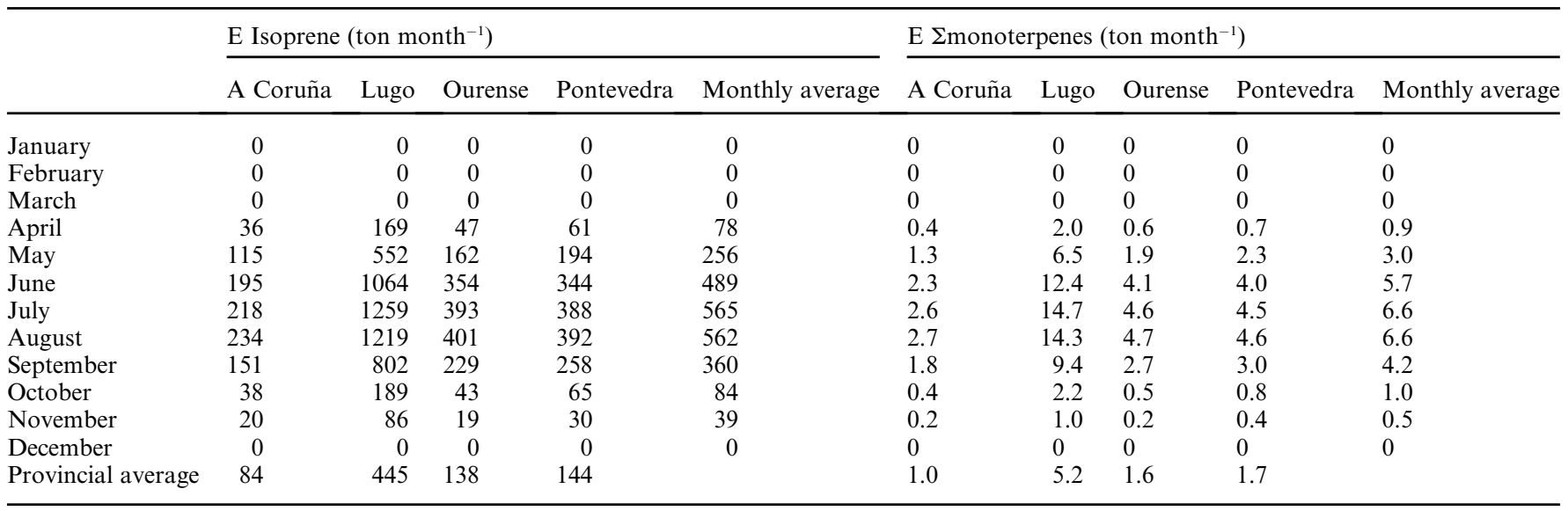

extension in Galicia being the third position occupied by Eucalyptus globulus. Eucalyptus emits also great quantities of isoprene, ${ }^{30}\left(E_{\mathrm{S}}\right.$ up to $69 \mu \mathrm{g} \mathrm{g}^{-1} \mathrm{~h}^{-1}$ ) which means that Galician forests are an important source of isoprene emissions.

\section{Uncertainties}

The cuvette or enclosure method has been widely used in order to determine the BVOC emissions at a leaf or at a branch scale. However, the extrapolation of the obtained data by this method up to a canopy or a regional scale must be done carefully because the errors associated with the scaling up are many. First of all, when we extrapolate the leaf measurements to the canopy level we are assuming that the behaviour of the sampled individual leaf is exactly the same as the behaviour of a heterogeneous forest cover. We are also considering that the solar radiation and the temperature are homogeneous all over the canopy. This is obviously not true, because the leaves are not all oriented in the same direction and the own canopy shields part of the foliage from sunlight. So with this extrapolation we are not taking into account the presence of both leaves in the sun and in the shade. In fact, Guenther et al. ${ }^{31}$ estimated that the isoprene emission rates for individual leaves can be up to a $75 \%$ higher than the emission rates measured using an entire branch. On the other hand, regarding the temperature, the canopy leads to an increase of the emissions because the temperature inside tends to be higher than ambient temperatures. Lamb et al. ${ }^{32}$ reported that increasing the leaf temperature from 25 to $30{ }^{\circ} \mathrm{C}$ causes a $70 \%$ increase in isoprene emissions, while doubling the available PAR can increase isoprene emissions by $100 \%$. We have conducted here the simplest approach, which assumes that the temperature and radiation within the canopy are the same as the ambient levels. As we have not used a canopy sunlight model our estimations of the total emissions are overestimated but, on the other hand, we are neither considering the influence of the canopy on the temperature, which produces an opposite effect.

Related to the meteorological data, it is also important to bear in mind that the number of meteorological stations recording both temperature and PAR is limited and their situation does not cover the total extension of Galicia. So, the subsequent estimations of the emissions are conditioned to these climatic data and sometimes they do not reflect the real characteristics of the Galician climate.

With regard to the composition of the forests, we have considered that in mixed forest the distribution of the forming species is egalitarian. This is often not true, however we have

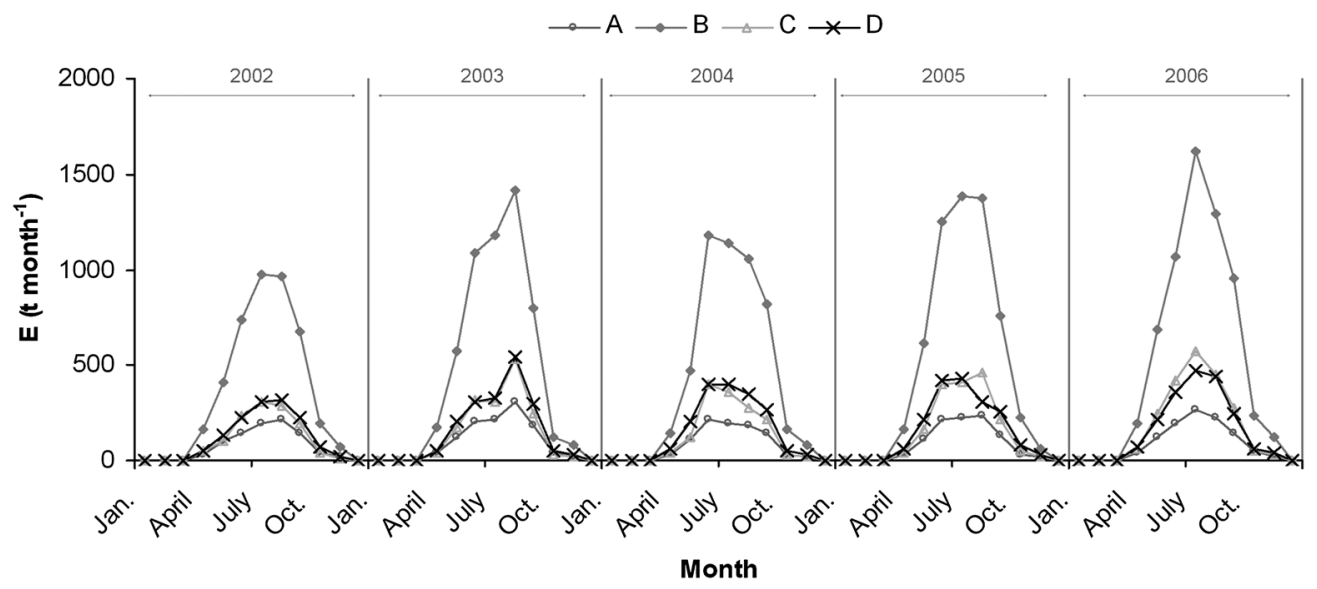

Fig. 3 Time course of the Quercus robur isoprene emissions in Galicia from 2002 to 2006. A: A Coruña; B: Lugo; C: Ourense; D: Pontevedra. 
used this approach in order to have a first preliminary estimation of the Quercus robur extension in mixed forests. In relation to the parameters used to estimate the biomass factors we have used an average value for the aerial biomass $\left(238 \mathrm{Mg} \mathrm{ha}^{-1}\right)$ to calculate the leaf biomass factor. However, the values of aerial biomass in Galician forests ranged from 136 to $385 \mathrm{Mg} \mathrm{ha}^{-1}{ }^{26}$ This means that the leaf biomass factor can vary approximately by a factor of \pm 1.7 , depending on the characteristics of the forest.

Apart from the considerations about the uncertainties in the extrapolation from the leaf-scale to the megaescale, it is important to emphasise that the uncertainty of the experimental data produces uncertainties in the results of the extrapolation. Thus, the precision of our experimental measurements, with variation coefficients lower than $8 \%$, and the uncertainty associated with the measures of the rotameter (less than $5 \%$ ) also affect the values obtained from the extrapolation.

\section{Conclusions}

Quercus robur is a strong isoprene emitter. It also emits monoterpenes. Among them, $\alpha$-pinene, $\beta$-pinene, and camphene emissions were measured in most of the samples and myrcene was found to be emitted occasionally. The standardised emission rates ranged from 43 to $73 \mu \mathrm{g} \mathrm{g}_{\mathrm{DM}}{ }^{-1} \mathrm{~h}^{-1}$ for isoprene and from 0.04 to $2.95 \mu \mathrm{g} \mathrm{g}_{\mathrm{DW}}{ }^{-1} \mathrm{~h}^{-1}$ for the sum of monoterpenes. The values found in the literature are within our experimental intervals.

Considering the calculated standardised emissions, meteorological data from 2002 to 2006 and the biomass and distribution of the Quercus robur stands in Galicia, we have estimated that the isoprene and monoterpene emissions fluctuated between 7691 and $11257 \mathrm{t} \mathrm{yr}^{-1}$ and from $90 \mathrm{t} \mathrm{yr}^{-1}$ to $132 \mathrm{t} \mathrm{yr}^{-1}$ respectively. This means that the isoprene averaged emission referred to the extension of the forests is $0.044 \mathrm{t} \mathrm{ha}^{-1} \mathrm{yr}^{-1}$, a value a bit lower than those reported in the literature.

\section{Acknowledgements}

D. Pérez-Rial is very grateful to the Xunta de Galicia for the concession of a PhD Grant and a fellowship to develop a research stay in the Department of Ecophysiology of the CSICCEAB-CREAF (Barcelona) during the development of this work. V. Fernández-Villarrenaga and G. Fernández-Martínez are gratefully acknowledged for their assistance in the analysis of the samples. JP acknowledges funding from grants from the Catalan Government (SGR2005-00312), and the Spanish Ministry of Education and Science (CGL2006-04025/BOS and Consolider Montes CSD2008-00040).

\section{References}

1 J. Kesselmeier and M. Staudt, J. Atmos. Chem., 1999, 33, 23.

2 J. Peñuelas and J. Llusià, Biol. Plant., 2001, 44, 481.

3 A. Calogirou, B. R. Larsen and D. Kotzias, Atmos. Environ., 1999, 33, 1423.

4 D. Kotzias, K. Fytianos and F. Geiss, Atmos. Environ., 1990, 24, 2127.

5 R. Atkinson and J. Arey, Atmos. Environ., 2003, 37, S197.
6 M. E. Davis and P. S. Stevens, Atmos. Environ., 2005, 39, 1765.

7 S. P. Pandis, S. E. Paulson, J. H. Seinfeld and R. C. Flagan, Atmos. Environ., 1991, 25, 997.

8 I. G. Kavouras, N. Mihalopoulos and E. G. Stephanou, Nature, 1998, 395,683 .

9 A. Van Donkelaar, R. V. Martin, R. J. Park, C. L. Heald, T. M. Fu, H. Liao and A. Guenther, Atmos. Environ., 2007, 41, 1267.

10 J. Peñuelas and J. Llusià, Trends Plant Sci., 2003, 8, 105.

11 A. Guenther, C. N. Hewitt, D. Erickson, R. Fall, C. Geron, T. Graedel, P. Harley, L. Klinger, M. Lerdau, W. A. McKay, T. Pierce, B. Scholes, R. Steinbrecher, R. Tallamraju, J. Taylor and P. Zimmerman, J. Geophys. Res., 1995, 100(D5), 8873.

12 DGCONA, (Dirección General de la Conservación de la Naturaleza), in III Inventario Forestal Nacional (1997-2006): Galicia. (Third National Forest Inventory (1997-2006): Galicia), Ed. ICONA, Ministerio de Medio Ambiente, Madrid, Spain, 2002.

13 A. B. Guenther, P. R. Zimmerman, P. C. Harley, R. K. Monson and R. Fall, J. Geophys. Res., 1993, 98(D7), 12609.

14 F. G. de la Torre, S. S. Casado, P. B. Alonso, L. R. N. Díaz, R. C. Guerrero, J. A. S. González and V. P. Muñuzuri, in Anuario Climatolóxico de Galicia 2002 (Galician Climatologic Yearbook 2002) ed. Consellería de Medio Ambiente and Centro de Desenvolvemento Sostible, Santiago de Compostela, Spain, 2002.

15 F. G. de la Torre, S. S. Casado, P. B. Alonso, L. R. N. Díaz, J. J. T. Hidalgo, R. C. Guerrero, J. A. S. González and V. P. Muñuzuri, in Anuario Climatolóxico de Galicia 2003 (Galician Climatologic Yearbook 2003) ed. Consellería de Medio Ambiente and Centro de Desenvolvemento Sostible, Santiago de Compostela, Spain, 2003.

16 F. G. de la Torre, S. S. Casado, P. B. Alonso, L. R. N. Díaz, J. J. T. Hidalgo, R. C. Guerrero, J. A. S. González and V. P. Muñuzuri, in Anuario Climatolóxico de Galicia 2004 (Galician Climatologic Yearbook 2004), ed. Consellería de Medio Ambiente and Dirección Xeral de Desenvolvemento Sostible, Santiago de Compostela, Spain, 2004.

17 F. G. de la Torre, S. S. Casado, P. B. Alonso, L. R. N. Díaz, J. J. T. Hidalgo, R. C. Guerrero, J. A. S. González and V. P. Muñuzuri, in Anuario Climatolóxico de Galicia 2005 (Galician Climatologic Yearbook 2005), ed. Consellería de Medio Ambiente e Desenvolvemento Sostible and Dirección Xeral de Desenvolvemento Sostible, Santiago de Compostela, Spain, 2005.

18 S. S. Casado, P. B. Alonso, L. R. N. Díaz, J. J. T. Hidalgo, R. C. Guerrero, J. A. S. González and V. P. Muñuzuri, in Anuario Climatolóxico de Galicia 2006 (Galician Climatologic Yearbook, 2006), ed. Consellería de Medio Ambiente e Desenvolvemento Sostible and Dirección Xeral de Desenvolvemento Sostible, Santiago de Compostela,Spain, 2006.

19 K. Dettmer, T. Knobloch and W. Engewald, Fresenius J. Anal. Chem., 2000, 366, 70.

20 V. Isidorov, J. Jaroszynska, T. Sacharewicz and E. Piroznikow, Atmos. Environ., 1999, 33, 4739.

21 C. N. Hewitt and R. A. Street, Atmos. Environ., 1992, 26, 3069.

22 D. Simpson, A. Guenther, C. N. Hewitt and R. Steinbrecher, J. Geophys. Res., 1995, 100(D11), 22,875.

23 P. Simeonidis, G. Sanida, I. Ziomas and K. Kourtidis, Atmos. Environ., 1999, 33, 3791.

24 G. Smiatek and R. Steinbrecher, Atmos. Environ., 2006, 40, S166.

25 A. Guenther, P. Zimmerman and M. Wildermuth, Atmos. Environ., 1994, 28, 1197.

26 M. A. Balboa-Murias, A. Rojo, J. G. Álvarez and A. Merino, Ann. For. Sci., 2006, 63, 557.

27 S. Andreani-Aksoyoglu and J. Keller, J. Atmos. Chem., 1995, 20, 71.

28 P. Symeonidis, A. Poupkou, A. Gkantou, D. Melas, O. D. Yay, E. Pouspourika and D. Balis, Atmos. Environ., 2008, 42, 1777.

29 C. Anastasi, L. Hopkinson and V. J. Simpson, Atmos. Environ., 1991, 25, 1403

30 C. He, F. Murray and T. Lyons, Atmos. Environ., 2000, 34, 645.

31 A. Guenther, P. Zimmerman, L. Klinger, J. Greenberg, C. Ennis, K. Davis, W. Pollock, H. Westberg, G. Allwine and C. Geron, J. Geophys. Res., 1996, 101(D1), 1345.

32 B. Lamb, D. Gay and H. Westberg, Atmos. Environ., 1993, 27, 1673. 